\title{
Neuroethology Meets Brain, Behavior and Evolution: Promoting the Study of the Neural Basis of Behavior
}

\author{
Shaun P. Collin ${ }^{a}$ N. Justin Marshall ${ }^{b}$ \\ aSchool of Life Sciences, La Trobe University, Bundoora, VIC , Australia; \\ ${ }^{b}$ Queensland Brain Institute, University of Queensland, St Lucia, QLD, Australia
}

This special issue of Brain, Behavior and Evolution represents the integration of two complementary or indeed overlapping research areas: neuroethology and the evolution of brains and behavior. Both attempt to illuminate the neural bases of behavior in a range of organisms. This special issue was initiated and made possible by S. Karger AG and their generous sponsorship of the International Congress of Neuroethology (https://www. neuroethology.org/Portals/2/ICN2018-Program-Book. pdf) held in Brisbane, QLD, Australia, in 2018. The conference, a now biennial event through the international society of the same name (ISN https://www.neuroethology.org/), brought together over 500 comparative neurobiologists that focus their research efforts on nervous system structure, function, development, behavior, and evolution in vertebrates and invertebrates using a range of techniques, both old and new.

To our delight, there was a lot of interest in contributing to this special issue and the chosen works form a collection of 6 articles covering visual and auditory processing, vocal communication, visual foraging, and the environmental drivers of sleep and wakefulness. The papers include a wide taxonomic range of animals: flies, sharks and rays, toads, birds, and bats, and the issue contains four original articles and two mini-reviews.

\section{KARGER}

() 2019 S. Karger AG, Basel

E-Mail karger@karger.com

www.karger.com/bbe
Guillet et al. [2019] investigates the link between energetic requirement and investment into sensory (visual) structures by comparing a strain of flies reared in the dark for 60 years to a strain, derived from this stock, that has been returned to normal light-dark cycles for the past five years. This study reveals that investment into visual structures (as measured by brain size and the relative importance of visual versus olfactory neuropils) correlates with increased food consumption, thereby supporting the idea that potentially costly sensory structures are positively selected, at least in a context in which food is abundant. Hoffmann et al. [2019] shed light on the spatial and temporal response characteristics of visual neurons in the retinorecipient superficial layers of the superior colliculus of an echolocating bat in order to investigate the

We would like to dedicate this issue to the late John (Jack) Pettigrew, past President of the International Society for Neuroethology (1989-1992), a regular contributor to Brain, Behavior and Evolution and member of the J. B. Johnston Club for Evolutionary Neuroscience (also officially sponsored by S. Karger AG). Jack made an enormous contribution to comparative neuroscience across several of the senses and animal groups examined in this issue, and his scientific legacy will undoubtedly continue to inspire future generations. His passion, generosity of spirit, and intellect will be sorely missed.
Shaun P. Collin

School of Life Sciences

La Trobe University

Bundoora, VIC 3086 (Australia)

E-Mail s.collin@latrobe.edu.au 
relative importance of vision (neural basis for their ability to see in low light levels) and biosonar. They suggest that echolocating bats likely use spatial but not temporal summation of visual input to improve visual performance under dim-light conditions. Salazar et al. [2019] present an intriguing study of the visual system of a neglected group of nocturnal birds, the caprimulgids. They use visual field mapping and retinal topography to reveal that the visual system of the band-winged nightjar is specialized for its sit-and-wait/pursuit hunting strategy. Sotelo et al. [2019] describe cognitive and neuronal aspects of spatial navigation in a toad. They reveal that male toads can learn the location of a reward guided by a mating call and that navigational ability is associated with greater neuronal activity in various structures within the telencephalon.

The two reviews capture the latest debates on vocal communication in birds and the behavioral and physiological indicators of sleep in sharks and rays. Elie et al.
[2019] examines the role of sender and receiver and the neural mechanisms that underlie the reciprocal exchange of information during communication in birds. They discuss research that focuses on the perception of the repertoire of songbird vocalizations, evaluation of vocalizations in mate choice, and the coordination of duet singing. In the review by Kelly et al. [2019], the behavioral and electrophysiological criteria for sleep are discussed for the first time in cartilaginous fishes (sharks and rays), including differentiating between buccal pumping and ram ventilating species of sharks. They compare what is known about the behavioral criteria defining sleep in bony fishes (sustained periods of immobility, circadian rhythm, high arousal threshold) and pose a series of hypotheses regarding the evolution of sleep and wakefulness in elasmobranchs.

We hope you enjoy reading these insightful articles that certainly help bridge the gap between neuroethology and the study of brain, behavior, and evolution.

\section{References}

Elie JE, Hoffmann S, Dunning JL, Coleman MJ, Fortune ES, Prather JF. From perception to action: The role of auditory input in shaping vocal communication and social behaviors in birds. Brain Behav Evol. 2019;94(1-4):61-70.

Guillet A, Stergiou A, Carle T. Effect of light exposure upon food consumption and brain size in dark-flies (Drosophila melanogaster). Brain Behav Evol. 2019;94(1-4):18-26.
Hoffmann S, Bley A, Matthes M, Firzlaff U, Luksch $\mathrm{H}$. The neural basis of dim-light vision in echolocating bats. Brain Behav Evol. 2019; 94(1-4):51-60.

Kelly ML, Collin SP, Hemmi JM, Lesku JA. Evidence for sleep in sharks and rays: Behavioural, physiological, and evolutionary considerations. Brain Behav Evol. 2019;94(1-4): $37-50$.
Salazar JE, Severin D, Vega-Zuniga T, FernándezAburto P, Deichler A, Sallaberry AM, et al. Anatomical specializations related to foraging in the visual system of a nocturnal insectivorous bird, the band-winged nightjar (Aves: Caprimulgiformes). Brain Behav Evol. 2019; 94(1-4):27-36

Sotelo MI, Bingman VP, Muzio RN. The mating call of the terrestrial toad, Rhinella arenarum, as a cue for spatial orientation and its associated brain activity. Brain Behav Evol. 2019; $94(1-4) ; 7-17$. 